University of Northern lowa

UNI ScholarWorks

Faculty Publications

Faculty Work

8-2017

\title{
Plant Size and Competitive Dynamics along Nutrient Gradients
}

Deborah E. Goldberg

University of Michigan - Ann Arbor

Jason P. Martina

University of Michigan - Ann Arbor

See next page for additional authors

Let us know how access to this document benefits you

Copyright (C2017 The American Society of Naturalists.

Follow this and additional works at: https://scholarworks.uni.edu/bio_facpub

Part of the Biology Commons

\section{Recommended Citation}

Goldberg, Deborah E.; Martina, Jason P.; Elgersma, Kenneth J.; and Currie, William S., "Plant Size and Competitive Dynamics along Nutrient Gradients" (2017). Faculty Publications. 19.

https://scholarworks.uni.edu/bio_facpub/19

This Article is brought to you for free and open access by the Faculty Work at UNI ScholarWorks. It has been accepted for inclusion in Faculty Publications by an authorized administrator of UNI ScholarWorks. For more information, please contact scholarworks@uni.edu. 
Authors

Deborah E. Goldberg, Jason P. Martina, Kenneth J. Elgersma, and William S. Currie 


\title{
Plant Size and Competitive Dynamics along Nutrient Gradients
}

\author{
Deborah E. Goldberg, ${ }^{1, *}$ Jason P. Martina, ${ }^{1,2}$ Kenneth J. Elgersma, ${ }^{3}$ and William S. Currie ${ }^{4}$
}

1. Department of Ecology and Evolutionary Biology, University of Michigan, Ann Arbor, Michigan 48109; 2. Department of Ecosystem Science and Management, Texas A\&M University, College Station, Texas 77843; 3. Department of Biology, University of Northern Iowa, Cedar Falls, Iowa 50614; 4. School of Natural Resources and Environment, University of Michigan, Ann Arbor, Michigan 48109

Submitted June 30, 2016; Accepted December 7, 2016; Electronically published May 15, 2017

Online enhancements: supplemental material. Dryad data: http://dx.doi.org/10.5061/dryad.4n0ff.

\begin{abstract}
AвSTRACT: Resource competition theory in plants has focused largely on resource acquisition traits that are independent of size, such as traits of individual leaves or roots or proportional allocation to different functions. However, plants also differ in maximum potential size, which could outweigh differences in module-level traits. We used a community ecosystem model called MONDRIAN to investigate whether larger size inevitably increases competitive ability and how size interacts with nitrogen supply. Contrary to the conventional wisdom that bigger is better, we found that invader success and competitive ability are unimodal functions of maximum potential size, such that plants that are too large (or too small) are disproportionately suppressed by competition. Optimal size increases with nitrogen supply, even when plants compete for nitrogen only in a size-symmetric manner, although adding size-asymmetric competition for light does substantially increase the advantage of larger size at high nitrogen. These complex interactions of plant size and nitrogen supply lead to strong nonlinearities such that small differences in nitrogen can result in large differences in plant invasion success and the influence of competition along productivity gradients.
\end{abstract}

Keywords: invasive plants, wetland, optimal size, clonal plants, individual-based model, competitive ability.

\section{Introduction}

Nutrient gradients, whether natural or anthropogenic, represent some of the most important axes of plant biodiversity and are often associated with substantial differences in community structure, including species turnover (Cleland and Harpole 2010), species richness and diversity (Mittelbach et al. 2001; Bobbink et al. 2010), and success of invasive species (Zedler and Kercher 2004). Many of these changes in community structure are associated with changes in plant functional traits along nutrient gradients (Fonseca et al. 2000; Suding et al. 2005; Xia and Wan 2008; Ordoñez et al. 2010; Gough et al. 2012). Accordingly, theory has addressed how

\footnotetext{
* Corresponding author; e-mail: degold@umich.edu.

ORCIDs: Goldberg, http://orcid.org/0000-0002-7950-0432; Currie, http:// orcid.org/0000-0003-1975-0808.
}

Am. Nat. 2017. Vol. 190, pp. 000-000. (C) 2017 by The University of Chicago. 0003-0147/2017/19002-57085\$15.00. All rights reserved.

DOI: $10.1086 / 692438$ traits such as height, maximum relative growth rate, allocation to roots, and many others differentially affect the outcome of competition along nutrient gradients (Grime 1977; Tilman 1988, 1990; Dybzinski and Tilman 2007; Farrior et al. 2013).

Surprisingly, however, we are lacking in comprehensive theory on perhaps the most fundamental organismal traitsize - and how it influences competitive dynamics along nutrient supply gradients. Because plants have indeterminate growth and actual sizes of individuals may differ enormously within a population, we use maximum potential plant mass $\left(M_{\max }\right)$ as the relevant trait. High values of $M_{\max }$ have several potential advantages that may depend on nutrient supply. At high nutrients, plant species with potentially larger individuals can reach greater population-level carrying capacities (measured as biomass) than smaller species simply because of greater potential volume above- and belowground. However, when availability of a key nutrient is low, limiting net primary productivity (NPP), the greater potential populationlevel biomass of a larger size species may not be realized.

Plant size is also clearly a fundamental component of response to resources and resource competition, although many other traits will influence competitive ability for particular resources and in particular situations. Nevertheless, all else equal, larger plants can acquire a larger amount of resources and therefore are often argued to be better competitors (Grime 1977; Keddy 2001). Consistent with this argument, larger plants are well demonstrated to have stronger short-term competitive effects on smaller target plants in both pot and field experiments (Goldberg 1987; Gaudet and Keddy 1988; Goldberg and Landa 1991; Keddy et al. 2002; Vogt et al. 2010). On the other hand, competitive response or the ability to tolerate the presence of competitors is not always correlated with plant size (Goldberg and Landa 1991; Keddy et al. 1998).

While a short-term competitive advantage of large $M_{\max }$ is often apparent, this is not easily translated to the longterm population dynamic outcome of resource competition (Freckleton et al. 2009; Martorell and Freckleton 2014). One key reason is that competitive effects in most experi- 
ments are typically measured on components of fitness for a small portion of the life cycle and thus do not include demographic costs that affect population growth rate. Counteracting the benefits for individual resource acquisition and growth, greater $M_{\max }$ has at least two important potential demographic costs, both of which may have larger effects at low than at high nutrient availability. First, because larger plants require more resources for maintenance, even temporary resource shortages may increase mortality if sufficient resources cannot be stored (Goldberg and Novoplansky 1997). Second, if plants with larger $M_{\max }$ also have concomitant larger threshold sizes for reproduction (Tracey and Aarssen 2011, 2014) or must allocate more of a limiting resource to successfully reproduce (Falster et al. 2008), potentially larger taxa may be unable to accumulate sufficient resources to reproduce where nutrient availability is too low. In fact, Aarssen (2008) suggests that consequent higher reproductive efficiency for smaller plants may actually lead to a population dynamic competitive advantage over larger plants, although he does not address how this might shift along nutrient gradients.

Given these and other potential demographic costs, understanding the consequences of variation in plant size requires investigation of population dynamics, not just individual performance. Given the decadal and longer timescales of population dynamics for most plants, models can provide a useful tool for this exploration. However, despite the emphasis on size per se from experimental studies of plant competition, resource competition theory has focused largely on resource acquisition traits that can be measured independent of size. These include traits at the module level (e.g., individual leaves or roots; Smith and Huston 1989; Tilman 1990, Clark et al. 2005) or whole-plant proportional allocation assuming constant total size (e.g., to leaves, stems, or roots; Tilman 1988; Farrior et al. 2013). The main exception to this general focus on size-independent traits in plant competition theory is the use of maximum potential height as an indicator of competitive ability for light (Givnish 1982; Smith and Huston 1989; Westoby et al. 2002). While height and maximum mass are likely positively correlated in practice, modeling only height and light depletion cannot address the role of size in competition for nutrients and therefore how competitive dynamics change among environments that differ in nutrients.

In this study, we begin to address the lack of population dynamic theory on the role of size in competition among plants and how this depends on nutrient supply. We used a simulation model to ask two questions. First, do potentially larger plants always have a competitive advantage in longterm community dynamics as suggested by the conceptual frameworks and the experiments reviewed above? Given the potential costs of large size as well as its advantages, an alternative hypothesis is that competitive ability is a unimodal function of plant size within any environment (i.e., an optimal size exists). Second, how does the effect of size on competitive dynamics change with nutrient availability and the mode of competition? Are larger plants better competitors only at high nutrients, when light is limiting and therefore competition is size asymmetric, or is there a size advantage even when there is only size-symmetric competition, as is often expected for nutrients?

Answers to these questions could have important implications for community ecology, including which traits lead to competitive dominance in different environments and the role of competition for different resources and overall at low versus high productivity in community assembly, issues that have long been highly controversial in plant ecology (Grime 1977; Tilman 1988; Smith and Huston 1989; Goldberg 1990; Grace 1990; Rees 2013). Because we assess the effect of plant size on community dynamics by comparing success of plants grown alone versus invading a steady state community, answers to these questions also have more practical implications for the traits of successful invaders and how these are expected to change along eutrophication gradients (Van Kleunen et al. 2010).

We address these questions using a model of competition among clonal plants. Clonal plants dominate almost all perennial herbaceous communities, including most grasslands, tundra, and wetlands, yet the community consequences of clonality and clonal traits are only beginning to be explored (de Kroon and van Groenendael 1997; Herben and Suzuki 2001; Gough et al. 2002; Sosnova 2010; Zobel et al. 2010; Eilts et al. 2011; Gough et al. 2012; Oborny et al. 2012; Wildova et al. 2012; Dickson et al. 2014; Herben and Goldberg 2014). Clonal plants spread horizontally by establishment of new ramets (vegetatively produced, potentially independent modules) as part of a single genet. For clonal plants, we define $M_{\max }$, maximum potential size, as the maximum ramet size rather than the maximum genet size.

We use in silico experiments with a highly parameterized model of community dynamics rather than real plants to both isolate the effects of size without other potentially confounding traits and examine the long-term consequences to community dynamics of plant size in ways that would be impossible in real-time experiments. By using a complex simulation model parameterized from field data, we can nevertheless provide a realistic context for our results. We report on results from a community ecosystem model called MONDRIAN (Modes Of Nonlinear Dynamics, Resource Interactions, And Nutrient cycling) that integrates population dynamics of clonal plants with ecosystem function in wetland plant communities using richly detailed, highly mechanistic processes and interactions in a spatially explicit model (Currie et al. 2014; Martina et al. 2016). MONDRIAN follows in a long tradition of individual-based models in plant ecology (e.g., Botkin et al. 1972; Huston and Smith 1987; Smith 
and Huston 1989; Pacala et al. 1996; Herben and Suzuki 2001), although it is unique in its combination of explicit clonal growth mechanisms, richness of detail of nitrogen and carbon cycling, and attention to realistic values of a large number of both plant and environmental parameters.

We parameterized MONDRIAN for coastal marshes of the Laurentian Great Lakes to examine the interacting role of plant size and nutrient influx in the success of typical invaders in the region. These include large, clonal exotics such as Typha angustifolia L., Typha $\times$ glauca Godr., Phragmites australis (Cav.) Trin. ex Steud., and Phalaris arundinacea L. (Galatowitsch et al. 1999; Zedler and Kercher 2004; Farrer and Goldberg 2009) as well as native species dominant in high-nutrient wetlands of the region such as Typha latifolia L. (Keddy 1990).

To investigate changes in optimal $M_{\max }$ along nutrient gradients, we varied $M_{\max }$ only among simulated invader phenotypes while keeping all other plant traits constant across phenotypes, using field or literature-derived data to increase realism (see table 1 for parameter values and sources). The MONDRIAN model uses $M_{\max }$ as a species-specific parameter, although simulated individuals may or may not attain this size depending on resource availability and competition (described further below). Currie et al. (2014) have already shown that optimal size does indeed increase with nitrogen using this model, but that study focused exclusively on plants invading native vegetation and used an earlier version of MONDRIAN that did not incorporate light as a potentially limiting factor. In this study, we investigate the mechanisms behind changes in optimal maximum ramet mass by manipulating two additional aspects of the competitive environment along a nitrogen gradient. First, we incorporate or exclude interspecific competition by examining success of invaders of different $M_{\max }$ in the presence or absence of established resident vegetation. Second, we incorporate or exclude competition for light while keeping competition for nitrogen in all scenarios using a more recent version of MONDRIAN (Martina et al. 2016).

\section{Methods \\ Overview of the MONDRIAN Model}

MONDRIAN simulates the growth and reproduction of individual clonal ramets in a spatially explicit manner. It includes spatial ecosystem $\mathrm{C}$ and $\mathrm{N}$ cycling with detailed attention to mass balance and $\mathrm{C}: \mathrm{N}$ stoichiometries in above- and belowground plant organs, litterfall, decaying litter, and sediment organic matter. It assumes that $\mathrm{N}$ or light is the limiting resource and includes vertical translocations of $\mathrm{C}$ and $\mathrm{N}$ between individual stems and their associated rhizome nodes as well as horizontal $\mathrm{C}$ and $\mathrm{N}$ subsidies from parent

Table 1: MONDRIAN plant-related parameters and data sources

\begin{tabular}{|c|c|}
\hline Parameter & Value $^{\mathrm{a}}$ \\
\hline Maximum potential size as mass $\left(M_{\max }\right)$ & $.169, .535,1.691,5.345,16.914 \mathrm{~g}$ \\
\hline Maximum life span of rhizome nodes & 4 years \\
\hline Maximum relative growth rate ${ }^{\mathrm{b}}$ & $.069 \mathrm{~g} \mathrm{~g}^{-1} \mathrm{day}^{-1}$ \\
\hline Proportion of $\mathrm{C}$ from photosynthesis allocated belowground ${ }^{c}$ & .5 \\
\hline Ratio of maximum stem mass : maximum rhizome node mass for an individual ${ }^{\mathrm{c}}$ & $1: 1$ \\
\hline Target $\mathrm{C}: \mathrm{N}$ mass ratio for growth of aboveground stems ${ }^{c}$ & $18: 1$ \\
\hline Target $\mathrm{C}: \mathrm{N}$ mass ratio for growth of rhizome nodes ${ }^{\mathrm{c}}$ & $50: 1$ \\
\hline Proportion of green tissue $\mathrm{N}$ resorbed from senescing stems ${ }^{\mathrm{d}}$ & .46 \\
\hline First-order decomposition $(k)$ constant for litter ${ }^{\mathrm{e}}$ & .8 year $^{-1}$ \\
\hline Proportion of maximum stem $\mathrm{C}$ that must be available for new stem allocation ${ }^{c}$ & .1 \\
\hline Maximum angle for directional rhizome growth ${ }^{\mathrm{b}}$ & $43^{\circ}$ \\
\hline Internode distance ${ }^{\mathrm{f}}$ & $4 \mathrm{~cm}$ \\
\hline Biomass-height function ${ }^{\mathrm{g}}$ (bio $=$ biomass $\mathrm{g} \mathrm{m}^{-2}$; height in meters) & $h=.34$ bio $^{.529}$ \\
\hline Light extinction polynomial function ${ }^{\mathrm{h}}\left(\right.$ bio $=$ biomass $\left.\mathrm{g} \mathrm{m}^{-2}\right)$ & $\%$ light $=.0004$ bio $^{2}-.1228$ bio +101.52 \\
\hline Proportion of individual plant height at which light environment is determined ${ }^{\mathrm{h}}$ & .75 \\
\hline Standing crop to achieve full shade ${ }^{\mathrm{h}}$ & $1,469 \mathrm{~g} \mathrm{~m}^{2}$ \\
\hline \multicolumn{2}{|l|}{ Notes: } \\
\hline \multicolumn{2}{|l|}{${ }^{a}$ All mass values refer to aboveground dry biomass. } \\
\hline \multicolumn{2}{|l|}{ b Wildova et al. (2007). } \\
\hline \multicolumn{2}{|l|}{ 'D. Goldberg and K. Elgersma, unpublished data; samples collected in Cheboygan Marsh, Cheboygan, MI. } \\
\hline \multicolumn{2}{|c|}{${ }^{\mathrm{c}}$ Sharma et al. (2006). } \\
\hline \multicolumn{2}{|c|}{${ }^{\mathrm{e}}$ Calibrated to establish the approximately correct litter layer mass in native community under oligotrophic conditions. } \\
\hline \multicolumn{2}{|c|}{${ }^{\mathrm{f}}$ Estimates based on typical values observed in Cheboygan Marsh, Cheboygan, MI. } \\
\hline${ }^{\mathrm{g}}$ D. Goldberg and R. Wildova, unpublished data; Typha spp. samples collected in Cheboygan & $C$ h \\
\hline
\end{tabular}


to daughter ramets within each clone. Community dynamics (e.g., coexistence, competitive exclusion, and dominance) and $\mathrm{C}$ and $\mathrm{N}$ cycling are emergent features at the plot scale, arising from individual- to community-level interactions and feedbacks. At the same time, simulated annual $\mathrm{N}$ inputs, cycling, regeneration, and plant uptake of $\mathrm{N}$ strongly regulate plant growth. The model operates on a daily time step. It is formulated through a set of algorithms in an object-oriented programming language (Visual Basic .NET). For more information about the basic operation of MONDRIAN, see Currie et al. (2014); the code is provided in the supplementary material, available online. ${ }^{1}$

At the start of each growing season in the model, no living aboveground stems are present in the simulated marshes, but perennial rhizome nodes have overwintered stores of $\mathrm{C}$ and $\mathrm{N}$. Once a rhizome node has a threshold level of $\mathrm{C}$ and $\mathrm{N}$, it establishes an aboveground stem and translocates the needed $\mathrm{C}$ and $\mathrm{N}$ aboveground. This newly established ramet then exerts a daily demand for $\mathrm{N}$ from its rhizome node based on its current ramet mass, maximum relative growth rate (RGR), and target $\mathrm{C}: \mathrm{N}$ stoichiometry (table 1 ). Ramet growth is limited by available $\mathrm{N}$ or by light, whichever results in the lower growth rate. The defined $\mathrm{C}: \mathrm{N}$ ratios in living tissue are targets because they drive uptake demand, but thereafter they are variable on an individual basis through $\mathrm{C}$ and $\mathrm{N}$ translocation.

Competition for nitrogen arises mechanistically from aggregate demand for $\mathrm{N}$ by the sum of biomass of all individuals of all species in each spatial grid cell relative to supply and regeneration of $\mathrm{N}$ in the grid cell (Currie et al. 2014). Thus, nutrient competition was modeled as size symmetric (Weiner and Thomas 1986), although experimental work has shown that it probably has some size asymmetry in reality (Rajaniemi 2002; Rajaniemi et al. 2003). Competition for light arises from light depletion by neighboring individuals as a function of their heights and height-specific biomass distributions together with light-depletion effects on the RGR of each target individual (see Martina et al. 2016 for details). MONDRIAN allows light competition to be included or not included (i.e., switched off) for an entire model run, allowing otherwise identical simulations to be directly compared. When light competition is not included, RGR is limited only by $\mathrm{N}$ uptake.

MONDRIAN also includes clonal ramet reproduction over the course of a growing season and complex translocation of $\mathrm{C}$ and $\mathrm{N}$ between parents and daughters within a clone (no seed reproduction is currently in the model). Individual ramets (which comprise an aboveground stem and a belowground rhizome node and roots) are connected in series, which snake irregularly (stochastically) through the area

1. Code that appears in The American Naturalist is provided as a convenience to the readers. It has not necessarily been tested as part of the peer review. but at present do not branch. In each clone, the newest individual attempts to expand horizontally throughout the growing season by establishing a new daughter in a twostep process. First, the parent must have enough $\mathrm{C}$ and $\mathrm{N}$ (a fixed proportion of $M_{\max }$ ) to establish a daughter rhizome node while retaining a certain amount of mass. Second, the new rhizome node must accumulate a threshold amount of $\mathrm{C}$ and $\mathrm{N}$ (also a fixed proportion of $M_{\max }$ ) to create a stem to complete the new ramet. It both competes on its own for $\mathrm{N}$ uptake and can receive translocated $\mathrm{C}$ and $\mathrm{N}$ subsidies from up to two parents back within the clone. Parents with adequate $\mathrm{C}$ or $\mathrm{N}$ storage can translocate $\mathrm{C}, \mathrm{N}$, or both to the daughter to help with new ramet establishment. As a result, $\mathrm{C}$ and $\mathrm{N}$ can be translocated spatially from a grid cell in which a parent may dominate $\mathrm{N}$ or light uptake into an adjacent cell where a small-size daughter may face competition. It is important to note that by making the ability to produce a new rhizome node and stem a fixed proportion of maximum potential size, phenotypes with larger $M_{\max }$ also have larger absolute resource requirements for reproduction, generating a trade-off between maximum potential size and reproductive success (Tracey and Aarssen 2014).

\section{Model Parameterization and Simulations}

We constructed five hypothetical phenotypes that were identical in all parameters except for $M_{\max }$. Parameter values other than $M_{\max }$ were selected as averages across typical coastal marsh species in the Laurentian Great Lakes region, such as Schoenoplectus spp., Carex spp., Eleocharis spp., and Typha spp. Light competition traits are mainly derived from Typha spp. (table 1). For $M_{\max }$ we used a series of five discrete values that ranged over a logarithmic scale from 0.169 to $16.9 \mathrm{~g}$ (table 1). The smallest three sizes corresponded well with the field-measured ramet mass of common native species in our study region, Juncus balticus, Schoenoplectus americanus, and Schoenoplectus acutus, while the largest size corresponded well with Typha $\times$ glauca, a large-stature clonal plant that is invasive in many coastal marshes in the Laurentian Great Lakes region, particularly at high nitrogen levels (Farrer and Goldberg 2009; Tuchman et al. 2009). Resident communities always comprised mixtures of the three phenotypes with the three smallest values of $M_{\max }$, representing native vegetation of the region.

We analyze results of contrasting simulations, each lasting 40 model years, with a fully factorial design of five different invader sizes, presence or absence of an established resident community, light competition included or not, and six levels of $\mathrm{N}$ inflow. Each of the treatment combinations was simulated three times with stochastic differences (initial plant distributions and spatial movements during clonal reproduction). For treatments involving the presence of a preestablished resident community, the three smallest-size phe- 
notypes were established at intermediate densities of 65 genets per species introduced in each of four cohorts (in years 1 , 3,5 , and 7) randomly distributed throughout the area (model testing showed that this was a large enough number of genets that it never limited ramet densities or NPP). Subsequent growth in ramet densities and NPP was highly sensitive to nutrient inflows, but at a given nutrient level, the native community was stable in species composition and total NPP within 15 years. Therefore, invaders were introduced as fully grown individual ramets in two cohorts of 15 each, in years 15 and 20, randomly distributed throughout the area.

Each of the 10 experimental communities (five invader sizes, each alone or with residents) was simulated with light competition included or not at nine different levels of ecosystem $\mathrm{N}$ inflows ranging from 0.86 to $21 \mathrm{~g} \mathrm{~N} \mathrm{~m}^{-2} \mathrm{y}^{-1}$. The lowest value represents northern Michigan present day rainfed $\mathrm{N}$ deposition on the wetland surface only - that is, wet and dry inorganic $\mathrm{N}$ deposition plus atmospheric organic $\mathrm{N}$ deposition (Neff et al. 2002; NADP 2009). The highest value is typical of inflows from agricultural regions of the Great Lakes, although not the highest values observed. The area simulated was composed of 49 grid cells of $7.5 \mathrm{~cm} \times 7.5 \mathrm{~cm}$ each, for a total extent of $52.5 \mathrm{~cm} \times 52.5 \mathrm{~cm}$. To eliminate edge effects, the space was constructed as a torus: individuals moving off of any edge simply wrapped onto the opposite edge of the space. Data reported are for aboveground net primary productivity but are referred to as NPP in the text for simplicity.

\section{Model Sensitivity}

Previous MONDRIAN sensitivity analyses (Currie et al. 2014) suggest that invasion success and total community NPP are relatively robust to both plant (rhizome $\mathrm{C}$ and $\mathrm{N}$ requirements for clonal reproduction, relative growth rate, $\mathrm{C}: \mathrm{N}$ ratio for above- and belowground tissue, $\mathrm{N}$ resorption) and ecosystem (decay rate of litter and sediment organic matter, hydrologic flushing of $\mathrm{N}$, rate of detritus export, critical $\mathrm{C}: \mathrm{N}$ ratio of decomposition) parameters.

In this study, we also assessed sensitivity of the results to the number and size of grid cells relative to the standard of a $7 \times 7$ grid of $7.5 \times 7.5-\mathrm{cm}$ cells (total area $=0.27 \mathrm{~m}^{2}$ ) . Using a larger array of grid cells $(10 \times 10)$ resulted in decreased total NPP, but relative success of different sizes along the nitrogen gradient, the main focus of this article, did not change (fig. A1). Using larger grid cells $(15 \mathrm{~cm} \times 15 \mathrm{~cm})$ similarly reduced total NPP and also showed a small increase in the optimal $M_{\max }$ under any given competitive or nutrient condition but no qualitative changes from the patterns across competition and nutrient treatments reported below (fig. A1). Therefore, for computational ease, we retained the smaller grid cell size and number in the simulations reported here. Data underlying all figures are deposited in the Dryad Digital Repository: http://dx.doi.org/10.5061 /dryad.4n0ff (Goldberg et al. 2017).

\section{Results}

Successful invasions generally resulted in a 10-15-year transition period to a different but generally stable community composition (Currie et al. 2014). Given this approximate stability, we used the mean NPP of the population of each phenotype from 21-25 model years after the first attempted invasion, which we refer to as steady state NPP, as a measure of population performance for comparison among treatments. The small error bars within each set of three stochastic replicates of model runs illustrate the reproducibility of these steady states (fig. 1). Data underlying figures 1-3 are deposited in the Dryad Digital Repository: http://dx.doi.org /10.5061/dryad.4n0ff (Goldberg et al. 2017).

In 30 of the 36 analyses of size-dependent dynamics under different experimental conditions (different rates of $\mathrm{N}$ supply, presence or absence of residents, light competition included or not), invader population NPP at steady state peaked at some intermediate value of maximum potential mass, resulting in an optimal $M_{\max }$ within the range of sizes tested (fig. 1). Exceptions occurred in the absence of preestablished residents at the lowest two $\mathrm{N}$ levels, where the smallest-size invader had the highest NPP, and in the presence of residents at the two highest N levels, where the largestsize invaders had the highest NPP when light competition was included. Because these exceptions occurred at either end of the $\mathrm{N}$ gradient, the lack of an optimal $M_{\max }$ is likely due simply to limitations on the range of $M_{\max }$ tested (e.g., see the extended size range in fig. A1B).

In the absence of established residents (i.e., invasion into bare ground), optimal $M_{\max }$ increased with nitrogen (fig. 1). At the lowest N levels, steady state NPP declined almost linearly with increasing $M_{\max }$ such that the largest size tested $(16.0 \mathrm{~g})$ could not persist at all (NPP $=0$ at steady state). However, at higher $\mathrm{N}$ inflows, the largest-size invader had only slightly less NPP than the optimal size invader (fig. 1), indicating that in the absence of established residents, the disadvantage of large size declines with increasing inflow of N. Overall, the presence or absence of intraspecific light competition had relatively little effect on invader performance in the absence of established residents, although it did make a difference between persistence (albeit with low NPP) and nonpersistence for the largest size tested at low N.

Trends in performance differed dramatically for plants invading a resident community (fig. 1). Recall that the resident vegetation was a mixture of the three smaller sizes tested, so the three smallest invader phenotypes tested $(0.169,0.534$, and $1.69 \mathrm{~g} M_{\max }$ ) were the same size as at least one of the residents, while the two larger-size invaders were larger than any of the residents. The presence of established residents 

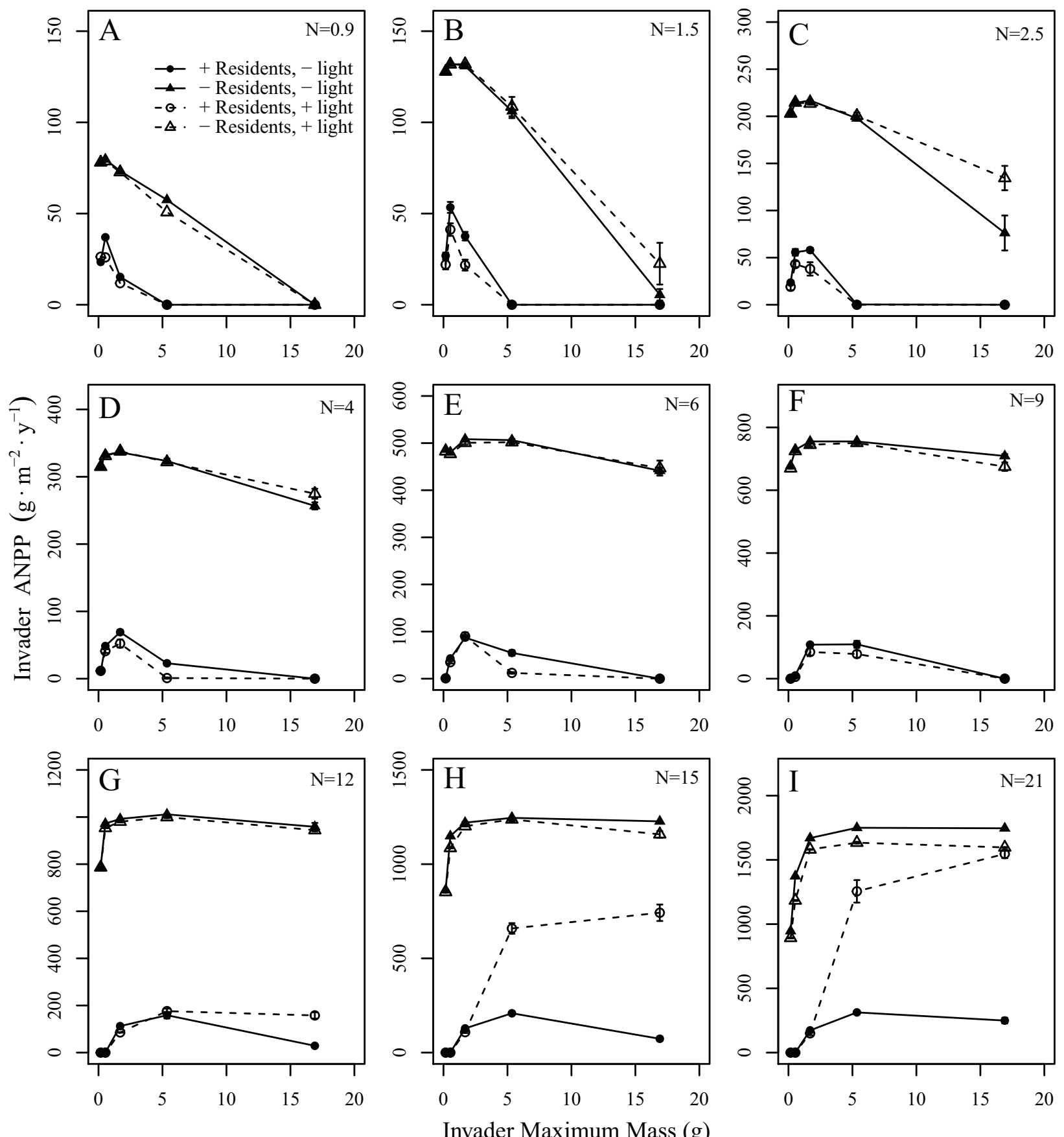

Figure 1: Aboveground net primary productivity (ANPP) of invaders as a function of maximum potential mass of an individual ramet $\left(M_{\max }\right)$ under different levels of nitrogen inflow (indicated in the upper right of each panel; $\mathrm{N}$ inflow $=0.9-21 \mathrm{~g} \mathrm{~N} \mathrm{~m}^{-2}$ year $^{-1}$ ) and scenarios of presence (plus sign) or absence (minus sign) of residents and of presence (plus sign) or absence (minus sign) of light competition. Competition for nutrients is present in all scenarios. Data are means and standard errors of three replicate simulations using the mean ANPP of years 21-25 after introducing invaders into either bare ground (absence) or steady state mixtures (presence) of residents comprising the three smallest size classes. Note that the scale of the $Y$-axis differs among panels. 
strongly inhibited invader NPP under most conditions, with two important exceptions. First, at the low nitrogen end, interspecific competition was inconsequential in invasion for the largest invaders tested, because they were unable to persist even in the absence of a resident community (fig. 1). The second exception was for the largest invaders at the high end of the nitrogen gradient in the presence of light competition, where they were able to completely dominate and exclude already established vegetation (fig. 2), performing just as well as they did with residents absent (fig. 1).

In contrast to the competitive advantage of large size at high nitrogen, at low to intermediate nitrogen, larger invaders were competitively excluded by residents, while smaller invaders were able to persist (fig. 1) although not dominate (fig. 2). As a consequence, with interspecific competition from established residents, smaller-size invaders largely declined in steady state NPP with increasing N, while larger-size invaders increased in steady state NPP with increasing nitrogen (fig. $3 C, 3 D$ ). This contrasts strongly with the increase in NPP with nitrogen regardless of invader size in the absence of competing residents (fig. $3 A, 3 B$ ).

Optimal size of invaders was typically larger when invading resident vegetation than when invading bare ground, al- though the effect was usually relatively small (fig. 1). Including competition for light as well as nutrients affected optimal size only at relatively high nitrogen; in fact, these are the only conditions in which interspecific competition of any kind had a large effect on optimal size. For the two highest $\mathrm{N}$ levels with light competition, the optimal size appeared to be as large or larger than the largest size tested, a considerable increase over the optimal size when light competition was not included (fig. 1). Even with successful invasion into established resident communities, invaders of ten coexisted with residents in the simulations, exceeding $50 \%$ of community biomass only at the two highest nitrogen levels and with light competition included (fig. 2).

\section{Discussion}

Our simulations reveal three key findings about the role of plant size in invasion along a nutrient gradient: invader NPP was generally a unimodal rather than a monotonic function of plant size, the optimal value of $M_{\max }$ increased with nitrogen availability, and optimal $M_{\max }$ increased with interspecific competition for nutrients (size symmetric) and, at high $\mathrm{N}$, with size-asymmetric light competition.

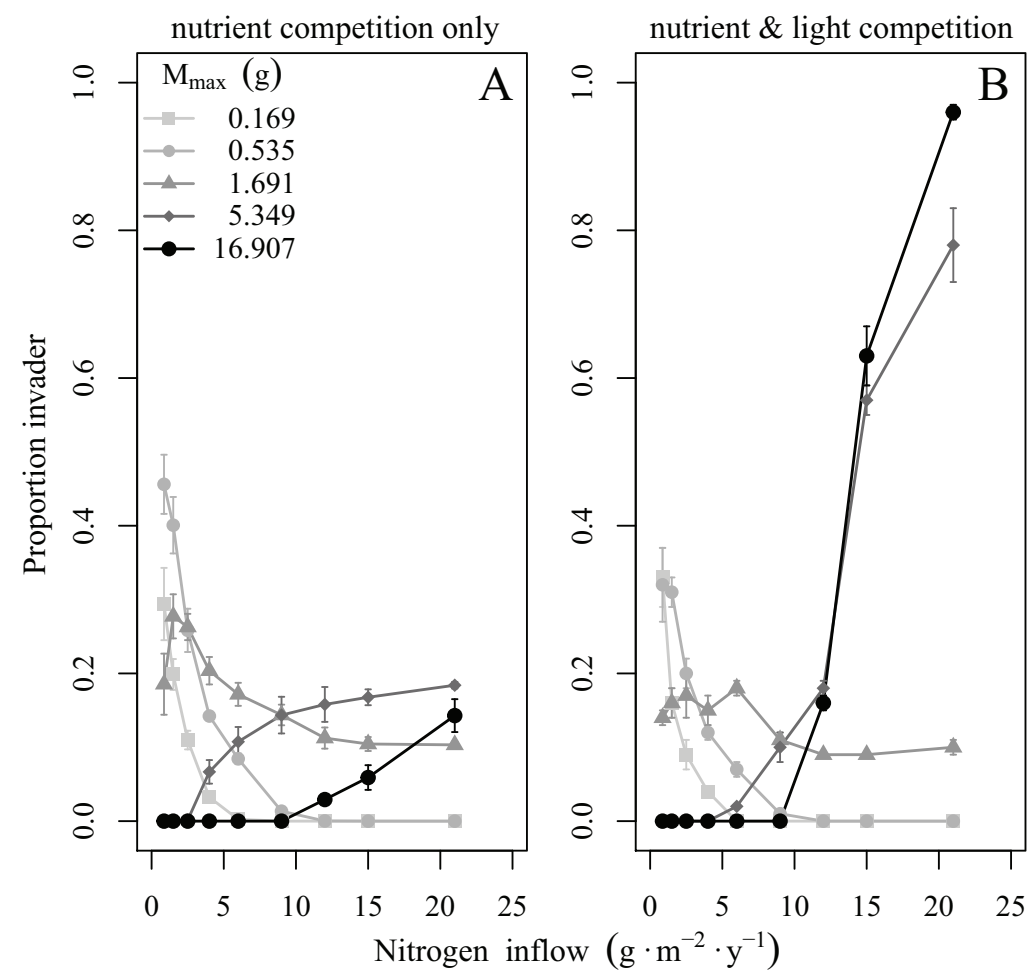

Figure 2: Proportion of total aboveground net primary productivity (ANPP) belonging to invaders of different maximum potential size as a function of nitrogen inflow under nutrient competition or light plus nutrient competition. Data are means and standard errors of three replicate simulations using the proportion of ANPP of invaders during years 21-25 after introducing invaders into steady state mixtures of residents comprising the three smallest size classes. 

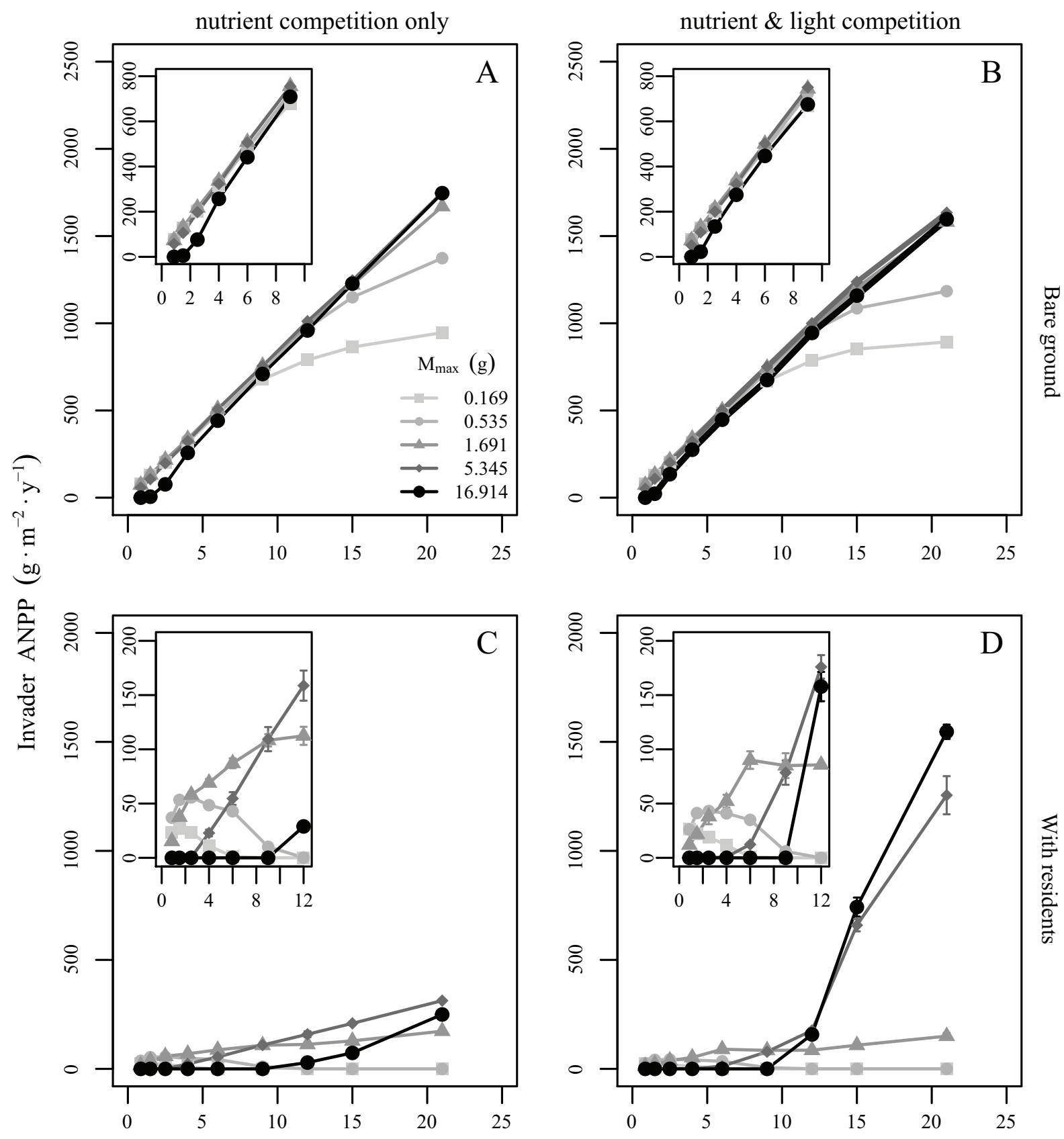

Nitrogen inflow $\left(\mathrm{g} \cdot \mathrm{m}^{-2} \cdot \mathrm{y}^{-1}\right)$

Figure 3: Response of invaders of different maximum mass to nitrogen inflow under different scenarios of presence or absence of residents and of nutrient competition or light plus nutrient competition. Data are means and standard errors of three replicate simulations using the mean ANPP of years 21-25 after introducing invaders into either bare ground (absence of residents; $A, B$ ) or steady state mixtures of residents $(C, D)$. Residents comprised a mixture of the three smallest size classes.

\section{Costs and Benefits of Large Size}

Contrary to the common expectation that large size conveys competitive ability across all environments (Grime 2001; Keddy 2001), relationships between $M_{\max }$ and inva- sion success were not monotonic. We tested the effects of a two order of magnitude range of potential plant mass and found that an intermediate size was optimal under the majority of simulated conditions. This optimum presumably represents the balance between the costs and ben- 
efits of large size, which shift with environmental conditions. One major benefit of large size in MONDRIAN is the ability to take up a larger amount of resources, which can increase subsequent survival and growth. This is only useful as long as sufficient resources (nutrients or light) are available so that individuals can approach this larger size. Larger size can also have advantages when competing with differentsize individuals; these are discussed below. The chief cost of large size in MONDRIAN is the higher absolute accumulation of resources needed for clonal reproduction; we modeled the minimum $\mathrm{C}$ or $\mathrm{N}$ required to make a new ramet as a fixed proportion of $M_{\max }$ (10\% in the simulations reported here). This cost of reproduction is reflected in lower population growth rates for larger species that have a higher absolute growth rate for individuals and illustrates one important mechanism for why the outcome of individual-level experiments do not necessarily scale up to population and community dynamics (Freckleton et al. 2009; Martorell and Freckleton 2014).

Given the importance of this cost for our results, it is critical to assess the validity of our assumption that minimum size for reproduction increases with $M_{\max }$. It seems reasonable for rhizomatous clonal organisms where the maternal plant has to completely subsidize production of belowground rhizomes and rhizomes are typically proportional in size to the aboveground stems they eventually support. Nevertheless, empirical data on allocation to new clonal offspring are surprisingly scarce. For two relatively small clonal plant species, we were not able to find a minimum size for reproduction: the intercept of the allometric relationship between the mass of nonphotosynthetic daughter ramets and their parent rhizome mass was zero (E. Batzer, K. Elgersma, J. Martina, and D. Goldberg, unpublished data). However, greater statistical power to detect nonzero intercepts within species as well as a much greater range of maximum plant sizes across species would be necessary to assess this assumption. The assumption of a minimum size for reproduction that increases with size does seem to hold for sexual reproduction; Tracey and Aarssen (2014) showed that potentially larger plants have larger minimum size requirements for reproduction across 35 species of herbaceous plants in an old field. Given the importance of this potential cost of large size for understanding the ecology of organism size in plants, the relationship between minimum reproductive size and maximum potential size, as well as other potential costs of large size, is an important area for future research in both clonal and nonclonal plants.

\section{Optimal Plant Size along Nitrogen Gradients}

The optimal $M_{\max }$ strongly depended on nitrogen even when invading into bare ground. In MONDRIAN, a node producing a ramet has a maximum longevity (4 years in these simulations, following Hogg and Wein 1987) but dies earlier if it does not accumulate enough $\mathrm{C}$ or $\mathrm{N}$ over two growing seasons to make a stem. When $\mathrm{N}$ inflow is low, large stems may simply not be able to accumulate enough $\mathrm{N}$ to make new daughter ramets before they die, and thus populations cannot persist over time. Simulations varying the allocation to new ramets support this interpretation of the disadvantage of large size at low nitrogen: increasing the threshold size required to make new ramets results in smaller optimal size and inability of large invaders to persist even in bare ground across much of the $\mathrm{N}$ gradient (fig. A2). Thus, small $M_{\max }$ is adaptive in nutrient-poor systems even in the absence of interspecific competition.

When competing for nutrients only (i.e., in the absence of light competition), competition with established residents increased the optimal invader size relative to invading bare ground. This initially seemed somewhat surprising because, for simplicity's sake, we modeled competition for nutrients as a perfectly size-symmetric process (Weiner and Thomas 1986; Schwinning and Weiner 1998). However, even a size-symmetric process of competition can lead to a sizeasymmetric outcome of competition when plants of different sizes compete (Schwinning and Weiner 1998). This point is not widely recognized but happens because both small and large plants lose some of their potential resource uptake due to competition. For a given absolute depletion of a limiting nutrient by a group of neighbors, the consequent reduction in growth is disproportionately larger for smaller plants because the loss is a greater proportion of their potential growth (Schwinning and Weiner 1998). Thus, potentially larger plants end up with a competitive advantage at a given nitrogen level. The increase in optimum size due to interspecific competition for nutrients only was relatively small (one size class at most) and, importantly, was similar in magnitude across the nitrogen loading gradient.

In contrast, consistent with empirical evidence that competition for light tends to be stronger at high nutrients (Wilson and Tilman 1991), the inclusion of interspecific light competition as well as nutrient competition increased optimal size only at high nutrients. In this analysis, we used the same $\mathrm{RGR}_{\max }$ across all species. In reality, across orders of magnitude in plant size, $\mathrm{RGR}_{\max }$ tends to decrease with size (Niklas and Enquist 2001), which, if it holds within our smaller range of plant size, would tend to mitigate the positive feedbacks we observed in large plants at high nutrient levels.

\section{Implications for Competition Theory}

The idea that larger plants are better competitors is pervasive in the literature and in fact is a central idea in one of the major conceptual models of plant community ecology: Grime's (1977) CSR theory. When only a narrow range of sizes is considered, our simulation results for population 
dynamics of different-size plants are indeed consistent with this idea: the optimal size at a given nitrogen level increases in the presence of interspecific competition. However, when a broader range of sizes is compared, it becomes clear that the competitive benefit of larger size exists only up to an optimal size; plants larger than the optimum are more suppressed by residents - that is, are in fact poorer response competitors than smaller plants, resulting in the unimodal relationship between invasion success and potential size within a given environment.

Our results also address long-standing debates about plant competition along productivity gradients. Grime $(1977,2001)$ has argued that the traits of good competitors, including large size, are independent of environment but that competition is unimportant at low productivity. In contrast, Tilman (1988) has argued that competition is an important process regardless of productivity, although the identity of the best competitor should switch between low and high productivity. More specifically, he predicted a trade-off between competitive ability for nutrients (key at low productivity) and for light (key at high productivity). Our results support elements of both frameworks. Consistent with Tilman's predictions, competition was important at both low and high productivity, as illustrated by the large differences in invasion success with versus without interspecific competition across the gradient. Also consistent with Tilman, small plants were more successful invaders at low productivity, while large competitors were more successful invaders at high nitrogen. However, this switch in competitive ability happened even when competition was only for nitrogen, so it was not due to a trade-off in competitive ability for light versus nitrogen. Furthermore, across the gradient, optimal size increased with interspecific competition, consistent with Grime's notion that larger plants are better competitors for all resources. This combination of results that is partially consistent and partially inconsistent with both frameworks is explained by a trade-off not present in either framework between maximum potential size, which is related to individual-level competitive ability for all resources, and ability to reproduce. Such a trade-off, where the cost is mainly in reproduction, will affect competitive ability only at the population level (i.e., when reproductive capacity influences competitive success). Thus, it would not be apparent in the individual-level experiments typically used to address the Grime-Tilman debates about the magnitude and nature of competitive ability (Goldberg 1990; Grace 1990; Goldberg et al. 1999).

Aarssen (2008) similarly argues for what he refers to as the reproductive efficiency hypothesis: small plants should have a competitive advantage because they can reproduce at smaller size and thus regenerate despite intense competition for resources (see also Tracey and Aarssen 2011, 2014; Aarssen et al. 2014). Our simulation results are consistent with Aarssen's conceptual model but also demonstrate that the reproductive efficiency hypothesis is most applicable when nutrient inputs are low, and therefore the higher absolute costs of reproduction for larger plants are unlikely to be met.

\section{Implications for Invasion Biology}

Our simulation results suggest that both invaders and natives should increase in $M_{\max }$ along nitrogen gradients and that successful invaders should be somewhat larger than native residents at any given nutrient level. Consistent with this prediction, in a meta-analysis of common garden and field experiments conducted in the invaded range, Van Kleunen et al. (2010) found that invasive species tended to be larger than co-occurring or related native species.

Our results also bear on the role of native vegetation in resisting invasion by exotics. Biotic resistance has been an important part of thinking about invasions since Elton (1958). In a meta-analysis, Levine et al. (2004) showed that competition from natives often plays a significant role in suppressing rates of spread of potential invaders in plant communities. While data are limited for the role of biotic resistance in completely excluding invaders (i.e., failed invasions), our simulation results highlight its potential importance, even when the invaders are highly successful growing in bare ground.

We also find strong effects of residents in suppressing productivity, even of successful and optimally sized invaders. Across most of the nitrogen gradient and for all but extremely large invaders, coexistence with natives is the norm in our simulations rather than dominance by the invader. This strong biotic resistance supports the idea that disturbance may be key in facilitating invasions because it eliminates resident populations that would inhibit invaders. Indeed, the large wetland invaders we simulated, such as Phragmites australis subsp. australis and Typha $\times$ glauca (whose $M_{\max }$ is comparable to the largest invader we modeled), may be able to establish dense monocultures in coastal wetlands of the Laurentian Great Lakes only during periods of low water when newly exposed bare soil is available for colonization (Tulbure et al. 2007; Wilcox 2012). However, our results also suggest that such large species can successfully invade and dominate even undisturbed native vegetation where nitrogen inflows are high enough.

\section{Conclusions}

Our conclusions about the existence of an optimal maximum potential size and its increase with interspecific competitive interactions and nitrogen supply come from a complex simulation model designed specifically for herbaceous clonal plants in wetlands, with no sexual reproduction. We nevertheless expect the key findings to be broadly applica- 
ble at least to herbaceous plants, most immediately because clonal plants dominate the herbaceous biomes of grasslands, wetlands, and tundra, which collectively cover ca. $17 \%$ of the global land surface (Bolin and Sukumar 2000). Second, although seedling establishment must be important for maintenance of genetic and to some extent species diversity in ecosystems dominated by clonal plants, it is probably much less important for patterns of abundance and dominance because of the sporadic nature of seedling establishment in these systems (Eriksson 1989). Consistent with this, Herben et al. (2014) found that clonal growth morphology explained more variation in local abundance than did seed production across 836 herbaceous species in the Czech Republic. More generally, competition is modeled mechanistically in MONDRIAN in a way that should apply to all plants, regardless of clonality, and as already noted, the assumption of a trade-off between maximum potential size and minimum reproductive size seems to be valid for sexual reproduction in at least herbaceous plants, regardless of clonality (Tracey and Aarssen 2014).

The results have important implications for competition theory, showing that plant size has more complex relationships to competitive ability than often assumed, that com- petition for nutrients can have important effects on community dynamics even when nutrient supply is high, and that interspecific competition can generate strong nonlinearities and thresholds in distribution and invasion potential. In turn, these theoretical conclusions have important management implications: in the presence of interspecific competition, the smallest invaders had a maximum $\mathrm{N}$ level above which they were unsuccessful, while the larger invaders had a minimum $\mathrm{N}$ level below which they were unsuccessful; these multiple thresholds suggest that small differences in nitrogen (or in land use that affects nitrogen supply) can have quite large effects on the risk of invasion.

\section{Acknowledgments}

We are grateful to numerous people for discussion of the ideas in this article, including J. Guittar, T. Herben, B. Oborny, and M. Price. Editors S. Harrison, M. Vellend, and A. Winn as well as several anonymous reviewers also helped improve the manuscript substantially. Funds were provided by the NASA Research Opportunities in Earth and Space Science (ROSES) program (grant NNX11AC72G) as well as the University of Michigan. 


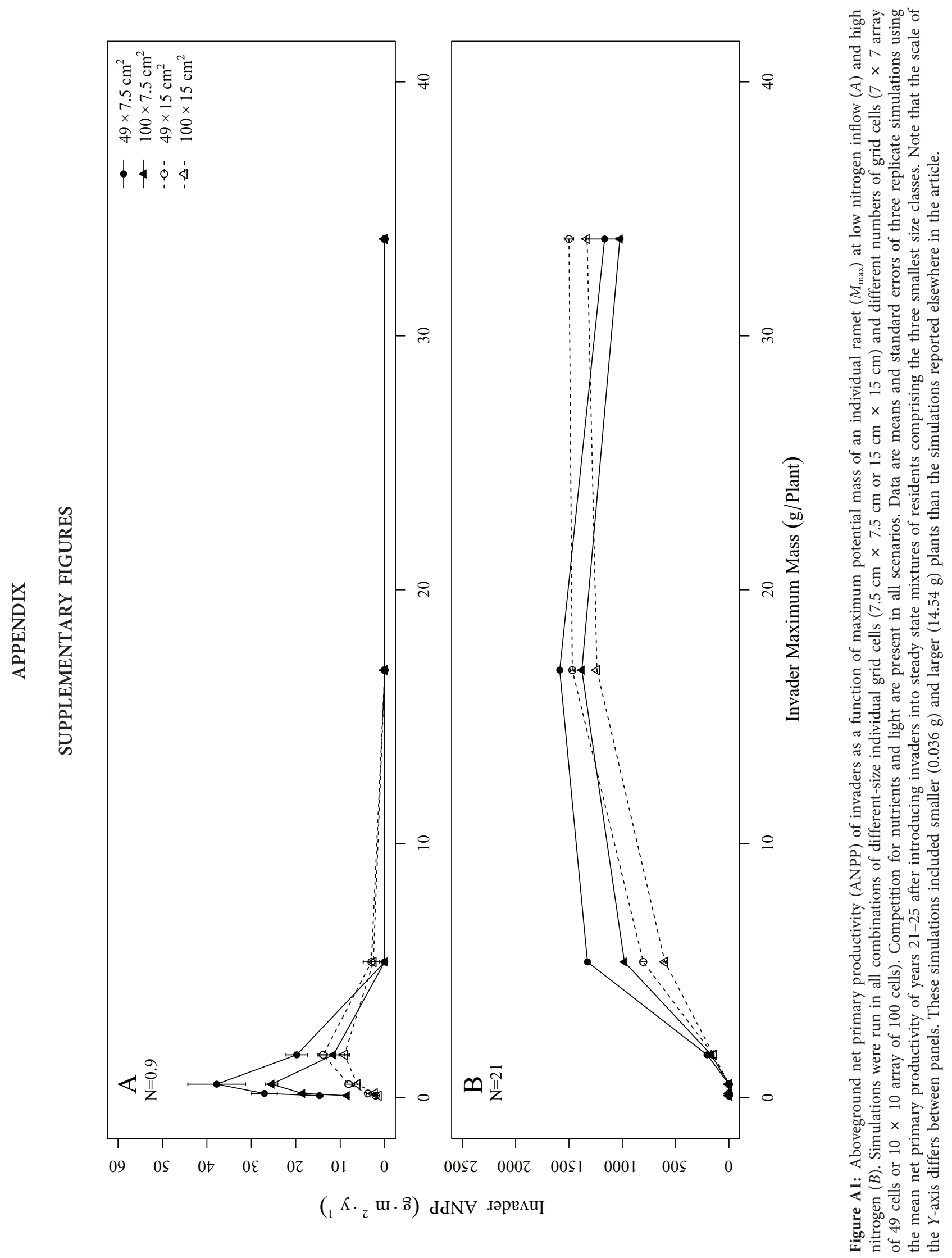

This content downloaded from 134.161.202.161 on June 13, 2017 13:14:11 PM 

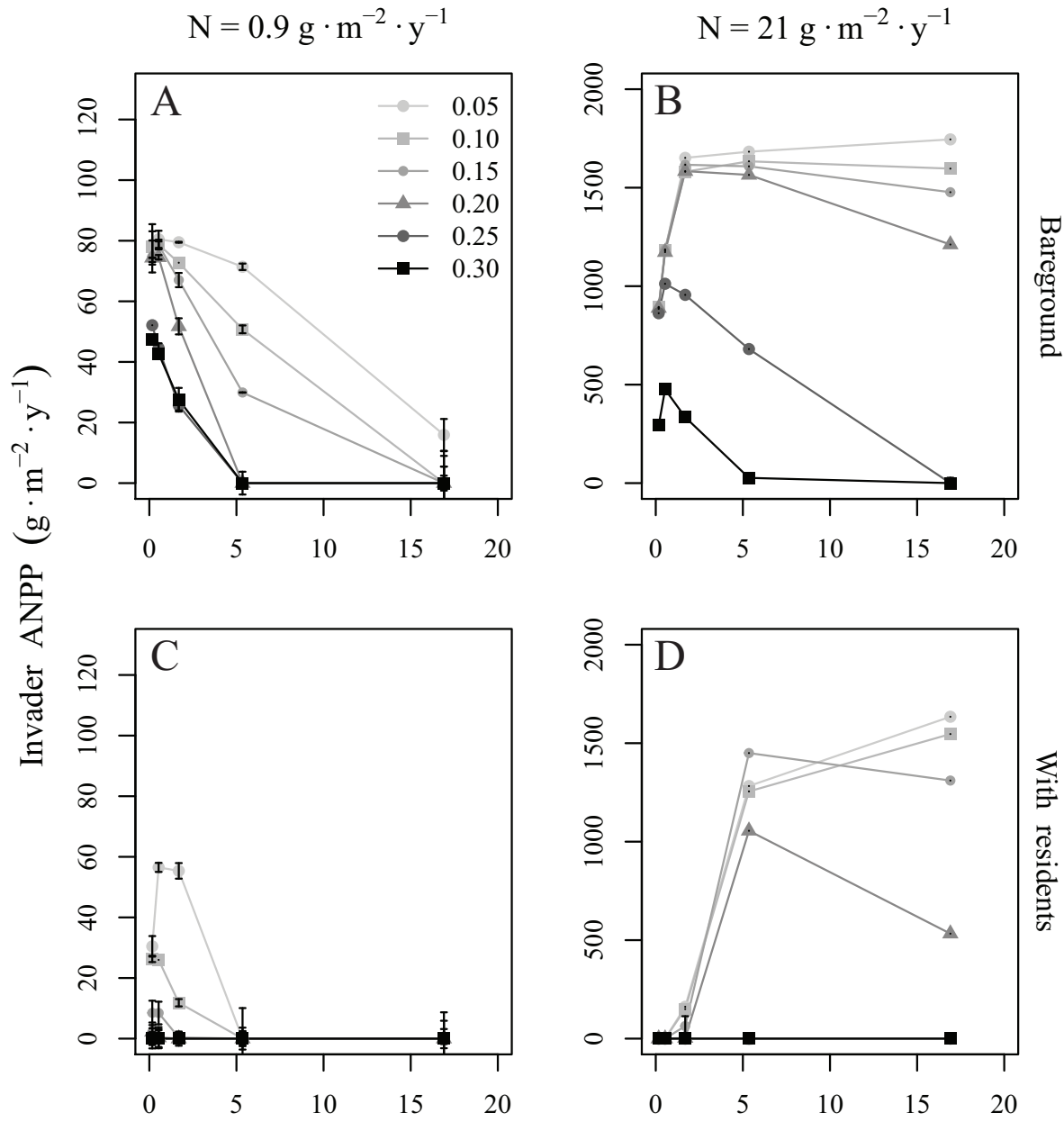

Invader Maximum Mass (g/Plant)

Figure A2: Aboveground net primary productivity (ANPP) of invaders as a function of maximum potential mass of an individual ramet $\left(M_{\max }\right)$ for simulations with different thresholds for resource accumulation before a new ramet of an invader can be produced, ranging from $5 \%$ to $30 \%$ of maximum potential mass. Results are shown for low nitrogen $(A, C)$ and high nitrogen $(B, D)$ and for invaders introduced into bare ground $(A, B)$ or into steady state mixtures of residents comprising the three smallest size classes $(C, D)$. Competition for nutrients and light are present in all scenarios. Data are means and standard errors of three replicate simulations using the mean net primary productivity of years 21-25 after introducing invaders. Note that the scale of the $Y$-axis differs between low and high nitrogen panels. Simulations reported elsewhere in this article all use $10 \%$ of maximum potential mass as the threshold accumulation of resources to produce a new ramet.

\section{Literature Cited}

Aarssen, L. W. 2008. Death without sex-the "problem" of the small and selection for reproductive economy in flowering plants. Evolutionary Ecology 22:279-298.

Aarssen, L. W., B. S. Schamp, and S. Wright. 2014. Big plants-do they affect neighborhood richness and composition in herbaceous vegetation? Acta Oecologica 55:36-42.

Bobbink, R., K. Hicks, J. Galloway, T. Spranger, R. Alkemade, M. Ashmore, M. Bustamante, et al. 2010. Global assessment of nitrogen deposition effects on terrestrial plant diversity of terrestrial ecosystems: a synthesis. Ecological Applications 20:30-59.

Bolin, B., and R. Sukumar. 2000. Global perspective. Pages 29-51 in R. T. Watson, I. R. Noble, B. Bolin, N. H. Ravindranath, D. J.
Verardo, and D. J. Dokken, eds. Land use, land-use change, and forestry. Special Report of the IPCC. Cambridge University Press, Cambridge.

Botkin, D. B., J. R. Wallis, and J. F. Janak. 1972. Some ecological consequences of a computer model of forest growth. Journal of Ecology 60:849-872.

Clark, B. R., S. E. Hartley, K. N. Suding, and C. de Mazancourt. 2005. The effect of recycling on plant competitive hierarchies. American Naturalist 165:609-622.

Cleland, E. E., and W. S. Harpole. 2010. Nitrogen enrichment and plant communities. Annals of the New York Academy of Sciences 1195:46-61.

Currie, W. S., D. E. Goldberg, J. Martina, R. Wildova, E. Farrer, and K. J. Elgersma. 2014. Emergence of nutrient-cycling feedbacks re- 
lated to plant size and invasion success in a wetland communityecosystem model. Ecological Modeling 282C:69-82.

de Kroon, H., and J. van Groenendael, eds. 1997. The ecology and evolution of clonal plants. Backhuys, Kerkwerve, Netherlands.

Dickson, T. L., G. G. Mittelbach, H. L. Reynolds, and K. L. Gross. 2014. Height and clonality traits determine plant community responses to fertilization. Ecology 95:2443-2452.

Dybzinski, R., and D. Tilman. 2007. Resource use patterns predict long-term outcomes of plant competition for nutrients and light. American Naturalist 170:305-318.

Eilts, J. A., G. Mittelbach, H. L. Reynolds, and K. L. Gross. 2011. Resource heterogeneity, soil fertility, and species diversity: effects of clonal species on plant communities. American Naturalist 177:574588.

Elton, C. 1958. The ecology of invasions by animals and plants. Methuen, London.

Eriksson, O. 1989. Seedling dynamics and life histories in clonal plants. Oikos 55:231-238.

Falster, D. S., A. T. Moles, and M. Westoby. 2008. A general model for the scaling of offspring size and adult size. American Naturalist 172:299-317.

Farrer, E., and D. E. Goldberg. 2009. Litter drives ecosystem and plant community changes in cattail invasion. Ecological Applications 19:398-412.

Farrior, C. E., D. Tilman, R. Dybzinski, P. E. Reich, S. A. Levin, and S. W. Pacala. 2013. Resource limitation in a competitive context determines complex plant responses to experimental resource additions. Ecology 94:2505-2517.

Fonseca, C. R., J. M. Overton, B. Collins, and M. Westboy. 2000. Shifts in trait-combinations along rainfall and phosphorus gradients. Journal of Ecology 88:964-977.

Freckleton, R. P., A. R. Watkinson, and M. Rees. 2009. Measuring the importance of competition in plant communities. $\underline{\text { Journal of }}$ Ecology 97:379-384.

Galatowitsch, S. M., N. O. Anderson, and P. D. Ascher. 1999. Invasiveness in wetland plants in temperate North America. Wetlands 19:773-755.

Gaudet, C. L., and P. A. Keddy. 1988. A comparative approach to predicting competitive ability from plant traits. Nature 334:242-243.

Givnish, T. J. 1982. On the adaptive significance of leaf height in forest herbs. American Naturalist 120:353-381.

Goldberg, D. E. 1987. Neighborhood competition in an old-field plant community. Ecology 68:1211-1223.

1990. Components of resource competition in plant communities. Pages $27-49$ in J. Grace and D. Tilman, eds. Perspectives in plant competition. Academic Press, Cambridge, MA.

Goldberg, D. E., and K. Landa. 1991. Competitive effect and response: hierarchies and correlated traits in the early stages of competition. Journal of Ecology 79:1013-1030.

Goldberg, D. E., J. P. Martina, K. E. Elgersma, and W. S. Currie. 2017. Data from: Plant size and competitive dynamics along nutrient gradients. American Naturalist, Dryad Digital Repository, http://dx.doi.org/10.5061/dryad.4n0ff.

Goldberg, D. E., and A. Novoplansky. 1997. On the relative importance of competition in unproductive environments. Lournal of Ecology 85:409-418.

Goldberg, D. E., T. Rajaniemi, J. Gurevitch, and A. Stewart-Oaten. 1999. Empirical approaches to quantifying interaction intensity: competition and facilitation along productivity gradients. Ecology 80:1118-1131.
Gough, L., D. E. Goldberg, C. Hershock, N. Pauliukonis, and M. Petru. 2002. Investigating the community consequences of competition among clonal plants. Evolutionary Ecology 15:547-563.

Gough, L., K. L. Gross, E. E. Cleland, C. M. Clark, S. L. Collins, J. E. Fargione, S. C. Pennings, and K. N. Suding. 2012. Incorporating clonal growth form clarifies the role of plant height in response to nitrogen addition. Oecologia 169:1053-1062.

Grace, J. B. 1990. On the relationship between plant traits and competitive ability. Pages 51-66 in J. Grace and D. Tilman, eds. Perspectives in plant competition. Academic Press, Cambridge, MA.

Grime, J. P. 1977. Evidence for the existence of three primary strategies in plants and its relevance to ecological and evolutionary theory. American Naturalist 177:1169-1194.

2001. Plant strategies, vegetation processes, and ecosystem properties. Wiley, London.

Herben, T., and D. E. Goldberg. 2014. Community assembly by limiting similarity vs. competitive hierarchies: testing the consequences of dispersion of individual traits. Journal of Ecology 102:156-166.

Herben, T., Z. Novakova, and J. Klimesova. 2014. Clonal growth and plant species abundance. Annals of Botany 114:377-388.

Herben, T., and J. I. Suzuki. 2001. A simulation study of the effects of architectural constraints and resource translocation on population structure and competition in clonal plants. Evolutionary Ecology 15:403-423.

Hogg, E. H., and R. W. Wein. 1987. Growth dynamics of floating Typha mats: seasonal translocation and internal deposition of organic matter. Oikos 50:197-205.

Huston, M., and T. Smith. 1987. Plant succession: life history and competition. American Naturalist 130:168-198.

Keddy, P. A. 1990. Competitive hierarchies and centrifugal organization in plant communities. Pages 266-290 in J. Grace and D. Tilman, eds. Perspectives in plant competition. Academic Press, Cambridge, MA.

- 2001. Competition. 2nd ed. Dordrecht, Netherlands.

Keddy, P. A., L. H. Fraser, and I. C. Wisheu. 1998. A comparative approach to examine competitive response of 48 wetland plant species. Journal of Vegetation Science 9:77-786.

Keddy, P. A., K. Nielsen, E. Weiher, and R. Lawson. 2002. Relative competitive performance of 63 species of terrestrial herbaceous plants. Lournal of Vegetation Science 13:5-16.

Levine, J. M., P. B. Adler, and S. G. Yelenik. 2004. A meta-analysis of biotic resistance to exotic plant invasions. Ecology Letters 7:975-989.

Martina, J., W. S. Currie, D. E. Goldberg, and K. E. Elgersma. 2016. Nitrogen loading leads to increased carbon accretion in both invaded and uninvaded coastal wetlands. Ecosphere 7:e01459. doi:10 $.1002 / \mathrm{ec} 2.1459$.

Martorell, C., and R. P. Freckleton. 2014. Testing the roles of competition, facilitation and stochasticity on community structure in a species-rich assemblage. Journal of Ecology 102:74-85.

Mittelbach, G. G., C. F. Steiner, S. M. Scheiner, K. L. Gross, H. L. Reynolds, R. B. Waide, M. R. Willig, S. I. Dodson, and L. Gough. 2001. What is the observed relationship between species richness and productivity? Ecology 82:2381-2396.

NADP (National Atmospheric Deposition Program). 2009. NRSP-3. NADP Program Office, Illinois State Water Survey, Champaign, IL.

Neff, J. C., E. A. Holland, F. J. Dentener, W. H. McDowell, and K. M. Russel. 2002. The origin, composition and rates of organic nitrogen deposition: a missing piece of the nitrogen cycle? Biogeochemistry 57:99-136. 
Niklas, K. J., and B. J. Enquist. 2001. Invariant scaling relationships for interspecific plant biomass production rates and body size. Proceedings of the National Academy of Sciences of the USA 98:2922-2927.

Oborny, B., C. Mony, and T. Herben. 2012. From virtual plants to real communities: a review of modelling clonal growth. Ecological Modelling 234:3-19.

Ordoñez, J. C., P. M. van Bodegom, J.-P. M. Witte, R. P. Bartholemeus, J. R. van Hal, and R. Aerts. 2010. Plant strategies in relation to resource supply in mesic to wet environments: does theory mirror nature? American Naturalist 175:225-239.

Pacala, S. W., C. D. Canham, J. Saponara, J. A. Silander, R. K. Kobe, and E. Ribbens. 1996. Forest models defined by field measurements: estimation, error analysis and dynamics. Ecological Monographs 66:1-43.

Rajaniemi, T. 2002. Why does fertilization reduce plant species diversity? testing three competition-based hypotheses. Iournal of Ecology 90:316-324.

Rajaniemi, T., V. K. Allison, and D. E. Goldberg. 2003. Root competition can cause a decline in diversity with increased productivity. Journal of Ecology 91:407-416.

Rees, M. 2013. Competition on productivity gradients - what do we expect? Ecology Letters 16:291-298.

Schwinning, S., and J. Weiner. 1998. Mechanisms determining the degree of size asymmetry in competition among plants. Oecologia 113:447-455.

Sharma, P., T. Asaeda, J. Manatunge, and T. Fujino. 2006. Nutrient cycling in a natural stand of Typha angustifolia. Journal of Freshwater Ecology 21:431-438.

Smith, T., and M. Huston. 1989. A theory of the spatial and temporal dynamics of plant communities. Vegetatio 83:49-69.

Sosnova, M., R. van Diggelen, and J. Klimesova. 2010. Distribution of clonal growth forms in wetlands. Aquatic Botany 92:33-39.

Suding, K. N., S. L. Collins, L. Gough, C. Clark, E. E. Cleland, K. L. Gross, D. G. Milchunas, and S. Pennings. 2005. Functional- and abundance-based mechanisms explain diversity loss due to $\mathrm{N}$ fertilization. Proceedings of the National Academy of Sciences of the USA 102:4387-4392.

Tilman, D. 1988. Plant strategies and the dynamics and structure of plant communities. Princeton University Press, Princeton, NJ.

- 1990. Mechanisms of plant competition for nutrients: the elements of a predictive theory of competition. Pages 117-141 in J. Grace and D. Tilman, eds. Perspectives in plant competition. Academic Press, Cambridge, MA.

Tracey, A. J., and L. W. Aarssen. 2011. Competition and body size in plants: the between-species tradeoff for maximum potential versus minimum reproductive threshold size. Iournal of Plant Ecology 4:115-122.
- 2014. Revising traditional theory on the link between plant body size and fitness under competition: evidence from old field vegetation. Ecology and Evolution 4:959-967.

Tuchman, N. C., D. J. Larkin, P. Geddes, R. Wildova, K. Jankowski, and D. E. Goldberg. 2009. Patterns of environmental change associated with Typha $\times$ glauca invasion in a Great Lakes coastal wetland. Wetlands 29:964-975.

Tulbure, M. G., C. A. Johnston, and D. A. Auger. 2007. Rapid invasion of a Great Lakes coastal wetland by non-native Phragmies australis and Typha. Lournal of Great Lakes Research 33:269-279.

Van Kleunen, M., E. Weber, and M. Fischer. 2010. A meta-analysis of trait differences between invasive and non-invasive plant species. Ecology Letters 13:235-245.

Vogt, D. R., D. J. Murrell, and P. Stoll. 2010. Testing spatial theories of plant coexistence: no consistent differences in intra- and interspecific interaction distances. American Naturalist 175:73-84.

Weiner, J., and S. C. Thomas. 1986. Size variability and competition in plant monocultures. Oikos 47:211-222.

Westoby, M., D. S. Falster, A. T. Moles, P. A. Vesk, and I. J. Wright. 2002. Plant ecological strategies: some leading dimensions of variation between species. Annual Review of Ecology and Systematics 33:125-129.

Wilcox, D. A. 2012. Response of wetland vegetation to the post-1986 decrease in Lake St. Clair water levels: seed-bank emergence and beginnings of the Phragmites australis invasion. ournal of Great Lakes Research 38:270-277.

Wildova, R., D. E. Goldberg, and T. H. Herben. 2012. The contrasting roles of growth traits and architectural traits in determining coexistence and competitive exclusion in clonal plants. American Naturalist 180:693-706.

Wildova, R., L. Gough, T. Herben, C. Hershock, and D. E. Goldberg. 2007. Architectural and growth traits differ in effects on performance of clonal plants: an analysis using a field-parameterized simulation model. Oikos 116:836-852.

Wilson, S. D., and D. Tilman. 1991. Components of plant competition along an experimental gradient of nitrogen availability. Ecology 72:1050-1065.

Xia, J., and S. Wan. 2008. Global response patterns of terrestrial plant species to nitrogen addition. New Phytologist 179:428-439.

Zedler, J. B., and S. Kercher. 2004. Causes and consequences of invasive plants in wetlands: opportunities, opportunists, and outcomes. Critical Reviews in Plant Sciences 23:431-452.

Zobel, M., M. Moora, and T. Herben. 2010. Clonal mobility and its implications for spatio-temporal patterns of plant communities: what do we need to know next? Oikos 119:802-806.

Associate Editor: Susan Harrison Editor: Alice A. Winn 